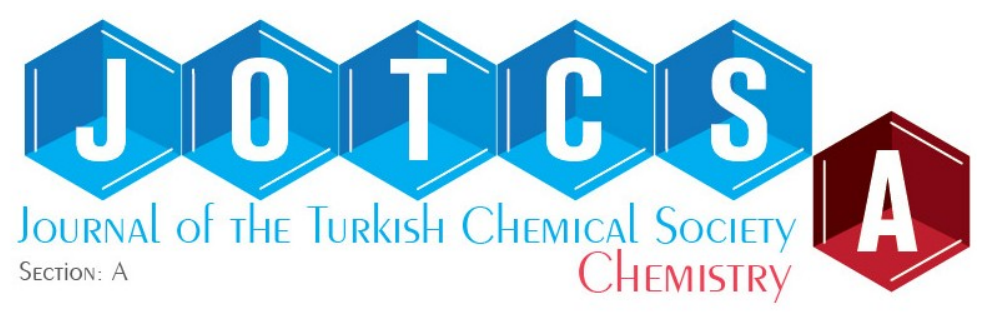

\title{
Synthesis of Polyaniline/Biochar Composite Material and Modeling with Nonlinear Model for Removal of Copper (II) Heavy Metal lons
}

\begin{abstract}
Halime YAKıŞıK ${ }^{1}$, Uğur ÖZVEREN ${ }^{2 *}$ D
${ }^{1}$ University of Marmara, Faculty of Engineering, Department of Chemical Engineering, 34722, İstanbul, TURKEY.

${ }^{2}$ University of Marmara, Faculty of Engineering, Department of Chemical Engineering, 34722, İstanbul, TURKEY.

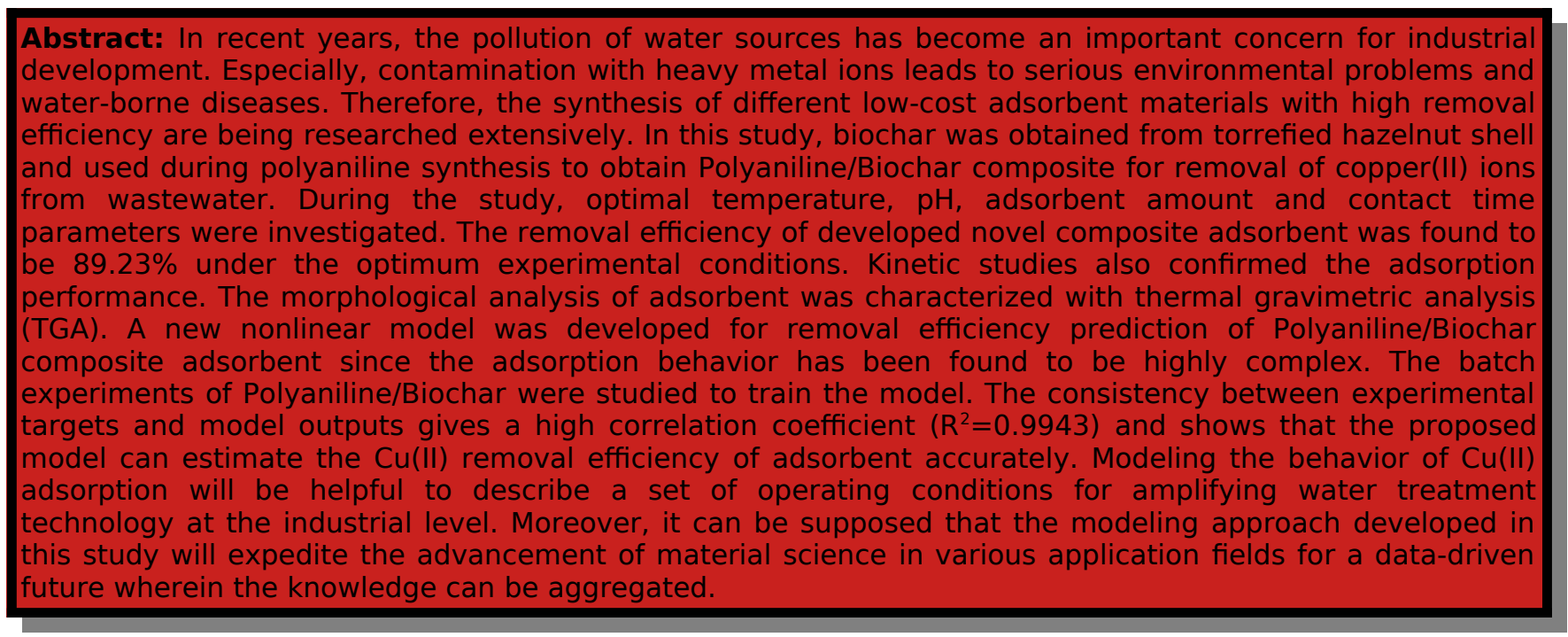

Keywords: Heavy metal removal, Copper(II), Biochar, Polymeric composite material, Modeling

Submitted: October 20, 2019. Accepted: January 07, 2021.

Cite this: Yakışık H, Özveren U. Synthesis of Polyaniline/Biochar Composite Material and Modeling with Nonlinear Model for Removal of Copper (II) Heavy Metal Ions. JOTCSA. 2021;8(1):289-302.

DOI: https://doi.org/10.18596/jotcsa.635073.

*Corresponding author. ugur.ozveren@marmara.edu.tr, GSM: +90 5358837701.

\section{INTRODUCTION}

With rapid population and industrial growth, many types of contaminants including dyestuff, pharmaceutical compounds, heavy metals can be found in water sources and considerably damage the environment (1). Long-term exposure of heavy metal ions occurs water-borne environmental pollution that causes serious health problems thanks to high-level toxin accumulation in human bodies (2, $3)$. In particular, copper is a common pollutant needed in various industries (automotive, pipes, valves, power plants, and electronics, etc.) due to its high electrical and thermal conductivity. However copper is widely used in different technologies, the toxicity of overload $\mathrm{Cu}$ uptake especially influences the liver as a target organ and causes acute poisoning. These environmental concerns have boosted the investigation of alternative recovery technologies for the $\mathrm{Cu}(\mathrm{II})$ removal. 
To date, a number of water treatment technologies have been employed for the removal of contaminants from water sources including coagulation-flocculation, biological oxidation, ionic exchange, electrochemical oxidation, adsorption, and membrane filtration (4-8). It is thought that the adsorption technique provides the most suitable alternative recovery to other treatment methods due to its more economical and simple application $(8,9)$. This recovery method is a well-known technology for heavy metal removal even at a very low ion concentration with a wide range of raw materials availability and low energy requirement (10). Researchers also have studied a set of adsorbents such as activated carbon (11), zeolites $(12,13)$, fly ash (14), polymers $(15-20)$, clays $(21$, $22)$ and agricultural wastes $(6,23,24)$ in the removal of heavy metal ions. Nonetheless, the production of effective adsorbents for acceptable water treatment mechanisms is still a challenge.

Biochar can be generated from almost all carbonaceous materials as a promising adsorbent for wastewater treatment with its remarkable chemical properties. As a waste management technique, the conversion of biomass waste into biochar has attracted attention because of its reusable properties. In addition, biomass sources have been identified as suitable adsorbent materials for different adsorption applications due to their enriched surface properties, cost-effective properties, and porous structures providing a wide surface area. Therefore, recent studies have been focused on the production of biochar using a wide variety of biomass wastes as a carbon source (straw, husk, sawdust, sludge residue, etc.) (25-28). On the other hand, application of biochar for wastewater recovery has been limited due to its low mechanical durability $(29,30)$. In studies where biomass wastes consisted only of lignin and cellulose, adsorbents showed low selectivity and mechanical resistance to heavy metal ions $(31,32)$. Therefore, recent studies have been focused on improving its potential practical applications for heavy metal removal through incorporation with various sorbent materials.

Modifying biochar with polymer matrices overcome the drawbacks of biochar and improve adsorption efficiency. In current decades, electroactive polymeric adsorbents such as polythiophene (PTh), polypyrrole (PPy) and polyaniline (PANI), find applications in multiple fields such as rechargeable batteries, microelectronics, composite materials, optics, biosensors, electronic devices, and adsorbents for wastewater recovery due to their doping and de-doping abilities (33-36). Among these polymeric composites, polyaniline (PANI) and its derivatives have attracted attention because of their specific characteristic properties including good redox reversibility, low-cost synthesis in aqueous solution, and ecological stability. Furthermore, PANI conducting polymer has shown high removal efficiency for heavy metal ions due to its ion exchange properties, and porous structure (37). Therefore, PANI adsorbents with their remarkable properties have been studied by researchers for the removal of heavy metal ions extensively due to functional amine and imine groups in their chains $(38,39)$

On the other hand, the large swelling during charge-discharge process often disrupts the mechanical stability of PANI (40). Therefore, carbonbased materials were utilized to support the mechanical structure and improve the electrochemical stability of PANI due to synergetic effect between PANI and carbon materials (41-43). However, some typical carbon-based materials used for PANI composites (such as carbon nanotubes, fullerene, and graphene) were synthesized via complex processes with limited and high-cost material sources (44-46). This is a crucial obstacle for commercial adsorbent applications of PANIcarbon based composites. Therefore, more attention requires to be focused on synthesis of PANI-carbon based composite adsorbent materials with comparable removal efficiency by using environmental, low-cost, and highly effective carbon rich materials as raw materials. On that note, biochar produced from different biomass sources have been considered as a promise to maintain significant characteristics such as high surface area, and excellent conductivity to the polyaniline structure (47). In current years, the utilization of PANI polymer onto the lignocellulosic biomass surface has been also examined to improve the properties and applicability of PANI (48). The PANIbased composites such as PANI/sawdust (49), and PANI/Argan-nut-shell (50) have indicated high removal capacity for aqueous pollutants. However, according to the best of our knowledge, no study has been reported for investigating the synergistic effect between biochar and Polyaniline as a carbonbased PANI composite adsorbent for wastewater treatment applications. Herein we synthesized a novel Polyaniline/Hazelnut Shell Biochar (PANI/BC) via in-situ chemical polymerization as a PANI-carbon based composite.

Beyond these, working conditions have a strong influence on adsorption capacity, which is largely dependent on all process variables. But evaluating the removal efficiency of synthesized adsorbent under different experimental conditions is a highly time-consuming and expensive method. Because, the wastewater treatment process is highly complex which are depended on all process variables and removal mechanisms. Therefore, aside from the experimental researches regarding adsorption studies, research is nowadays underway that seeks to employ modeling approach to understand which operational condition improves the removal efficiency. To our best knowledge, limited researches have been announced that concern the modeling and optimization of the removal process of 
adsorbent materials created in laboratories. Modeling of the adsorption process to understand the adsorption behavior is developed with an experimental run. The determination of removal percentage is the main factor that indicates the goodness of adsorption. Thus, it is essential to estimate the removal percentage in different experimental conditions. Therefore, the removal percentage was assigned as an output variable of the proposed model to clear the effect of each experimental parameters on the removal process.

The current study includes the development of a new nonlinear regression model that describes $\mathrm{Cu}(\mathrm{II})$ removal along with various operating conditions. The objective of this study is to develop and evaluate a novel predictive model for exploring the impact of different experimental parameters on $\mathrm{Cu}(\mathrm{II})$ removal efficiency using experimental datasets. The affecting parameters include the following: adsorbent dosage, $\mathrm{pH}$, adsorption time, and temperature, and all of which were preferred as input parameters and the model was developed by using model input parameters. The proposed model can estimate the removal efficiency of PANI/BC composite adsorbent as an output parameter. The validation of the proposed model was determined by investigating the adjustment of calculated and experimental results. A comparison between the calculated and experimental results gives the best fit for the adsorption efficiency prediction. This indicates the model is feasible for predicting the behavior of removal efficiency of $\mathrm{Cu}(\mathrm{II})$ ions. Finally, the nonlinear regression model we suggested in this study may improve the understanding of adsorption nature and may ease the conducting of adsorbent designs with increasing the selectivity towards specified heavy metal ions. According to our assumptions, the findings of this study also endow a new report on the modeling approach to demonstrate the opportunities of this technology having an advancement on material synthesis for various complex engineering approaches involving life and basic sciences in future.

\section{EXPERIMENTAL SECTION}

\section{Preparation of the biochar}

The hazelnut shells in the Black Sea region of Turkey were used for the preparation of the biochar. The biochar production from hazelnut shell samples was carried out under argon atmosphere using a vacuum oven (51). Biochar was produced at $200^{\circ} \mathrm{C}$ for 3 days. At the end of 3 days, the produced biochar samples were soaked in $50 \% \mathrm{H}_{2} \mathrm{SO}_{4}$ for 24 hours and then filtered using vacuum filtration technique. Sulfuric acid used during biochar synthesis increases the surface area of biochar, removes the ash content, and helps make biochar as a more effective adsorbent. Then, the biochar was purified with distilled water and dried at $110^{\circ} \mathrm{C}$. The dried biochar was ground with RETSCH ZM 200 Grinder device and was sieved using RETSCH AS 200 with grain size below $250 \mu \mathrm{m}$ for adsorption experiments.

\section{Synthesis of PANI/BC composite}

For the synthesis of PANI/BC composite hybrid material, $5 \mathrm{~mL}$ of aniline and $1 \mathrm{~g}$ of prepared biochar sample was dissolved in $70 \mathrm{~mL}$ of $\mathrm{HCl}(2 \mathrm{M})$ solution for 12 hours with stirring to prevent any particle aggregation. After 12 hours, $5 \mathrm{~g}$ of APS (Ammonium Persulfate) was dissolved in $20 \mathrm{~mL}$ of distilled water and slowly added to the solution for 10 minutes at constant stirring speed. Reaction mechanism of aniline polymerization through chemical oxidation was represented in Figure 1.

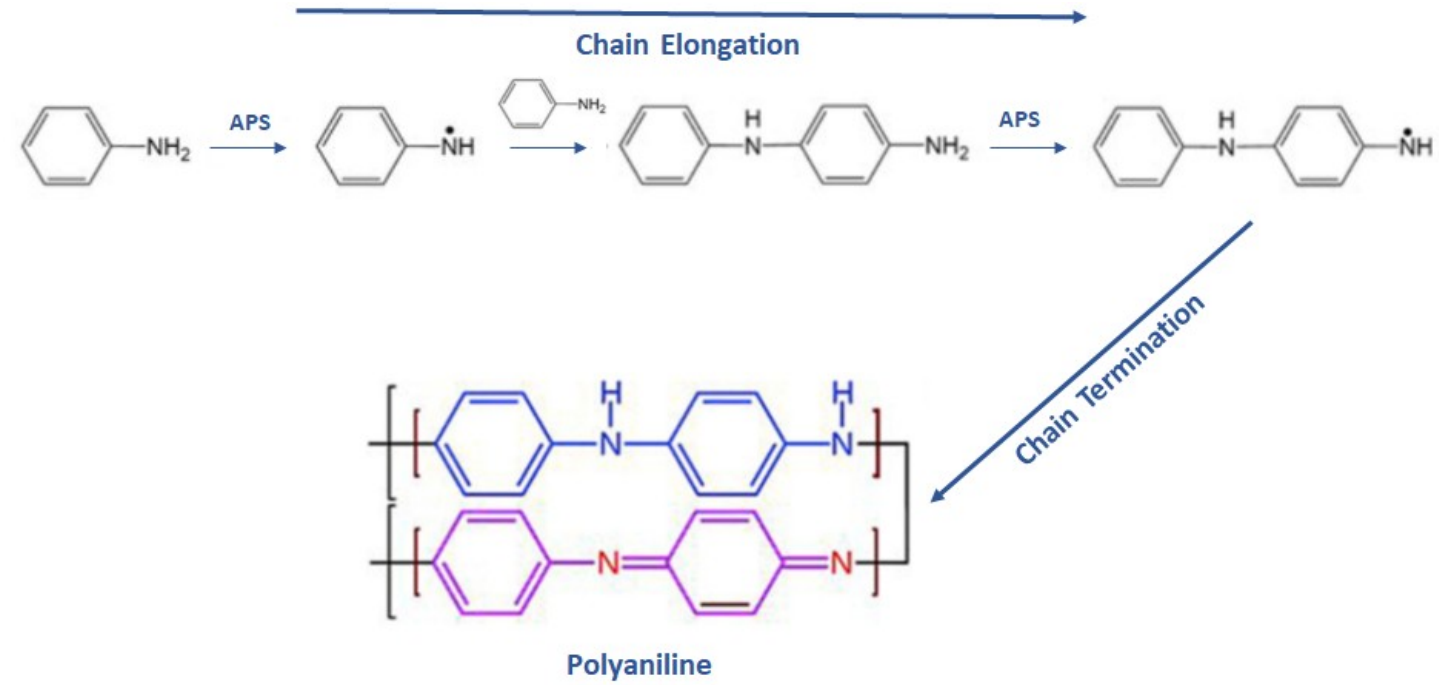

Figure 1. Polymerization mechanism of polyaniline $(52,53)$.

The polymerization was continued for 12 hours at a constant heating rate of $30^{\circ} \mathrm{C}$ and a constant stirring rate of $200 \mathrm{rpm}$. The Polyaniline/Biochar (PANI)/BC composite material was obtained as a result of the reaction and then was filtered. After filtration, the hybrid material samples were washed first with $\mathrm{HCl}$ 
(2M) solution, then with distilled water, and adsorbent samples were dehydrated in a vacuum oven at $90^{\circ} \mathrm{C}$ for 1 day $(54,55)$.

\section{Batch experiments for adsorption of $\mathrm{Cu}$ (II) ions}

To determine the adsorption features of Polyaniline/ Biochar (PANI/BC) composite, heavy metal adsorption experiments were carried out by using $\mathrm{Cu}$ (II) adsorption stock solutions. Chemicals and reagents were used of analytical grade. Cu(II) stock solutions (1000 $\mathrm{mg} / \mathrm{L})$ were prepared by dissolving copper(II) nitrate, $\mathrm{Cu}\left(\mathrm{NO}_{3}\right)_{2}$, in distilled water. The solutions were prepared by diluting the stock solutions to specific concentrations.

Adsorption experiments were performed adding certain amounts of adsorbent material into tubes containing $50 \mathrm{~mL}$ of metal ion solution. Adsorption process was conducted by mixing these solutions at different temperatures and at a constant stirring speed of $200 \mathrm{rpm}$. The $\mathrm{pH}$ values of the solutions were adjusted using $\mathrm{HCl}(1 \mathrm{M})$ or $\mathrm{NaOH}(1 \mathrm{M})$. On the other hand, the constant temperature of the adsorbent solutions was provided with a water bath. Adsorbents were removed from the solutions by using vacuum filtration technique at different time intervals $(5,15,30,60,120,180,240,300$, and 360 min) and adsorption capacities were calculated to make kinetic calculations. Copper removal experiments from aqueous solution was conducted by using batch experiments according to various experimental conditions such as pH (2-8), temperature $\left(18,20,25,30{ }^{\circ} \mathrm{C}\right)$, contact time $(5-$ $360 \mathrm{~min})$, and adsorbent dosage $(5-150 \mathrm{mg})$ to observe the effect of operational parameters on the removal efficiency.

At the end of the experiments, the adsorbents were removed from the solutions and filtered. The concentration of metal ions remaining in the solutions were determined using SHIMADZU, Double Beam UV-VIS Spectrophotometer/UV-2600 device. The percentage of metal ions was computed using the following equation.

$$
\text { Removal \% }=\frac{C_{0}-C_{e}}{C_{0}} \times 100
$$

Adsorption capacities were also computed using the following equation.

$$
q_{e}=\frac{\left(C_{0}-C_{e}\right) \times V}{W}
$$

Where $\mathrm{C}_{0}$ and $\mathrm{C}_{\mathrm{e}}$ are initial ion concentration of heavy metal ions $\left(\mathrm{mgL}^{-1}\right)$ and equilibrium concentration of heavy metal ions $\left(\mathrm{mgL}^{-1}\right)$ respectively. $\mathrm{V}$ represents the volume of adsorbate solution $(\mathrm{mL})$ and $\mathrm{W}$ is the adsorbent amount in (mg).

\section{RESULT and DISCUSSION}

\section{Characterization}

Thermal gravimetric analysis: The thermal stability of pure polyaniline, and Polyaniline/Biochar (PANI/BC) composite were determined with thermogravimetric analysis. Figure 2 indicates the thermal gravimetric plots of pure PANI (a) and PANI/ BC composite (b). The TGA characterization curve of pure PANI (Figure 2) shows three steps of mass loss: the first one takes place at around $100-200{ }^{\circ} \mathrm{C}$ with $6.98 \%$ weight loss accounting to the loss of adsorbed water molecules and dopant $\mathrm{HCl}$ molecules from polymer chains; second step at about $200-400{ }^{\circ} \mathrm{C}$ with a mass decline of $12.12 \%$ which was likely due to the discharge of protonic acid groups and the third step at about $400-750{ }^{\circ} \mathrm{C}$ with a weight decline of $37.22 \%$ is due to thermal decomposition of PANI chains and the fracture of the polymer chain (56). The thermogravimetric analysis of PANI/BC composite (Figure 2) demonstrates three phases of mass loss: the first step initiating at about $100-200{ }^{\circ} \mathrm{C}$ with a mass loss of $3.84 \%$, regarded as dehydration step of the adsorbed water molecules; second step occurred at about $200-380^{\circ} \mathrm{C}$ with a mass decrease of $11.41 \%$ as an outcome of the protonic acid groups removal and the final stage observed in between $380-700^{\circ} \mathrm{C}$ with a weight loss of $33.12 \%$ as a result of the fracture of polymer chain that governs the gas production. 


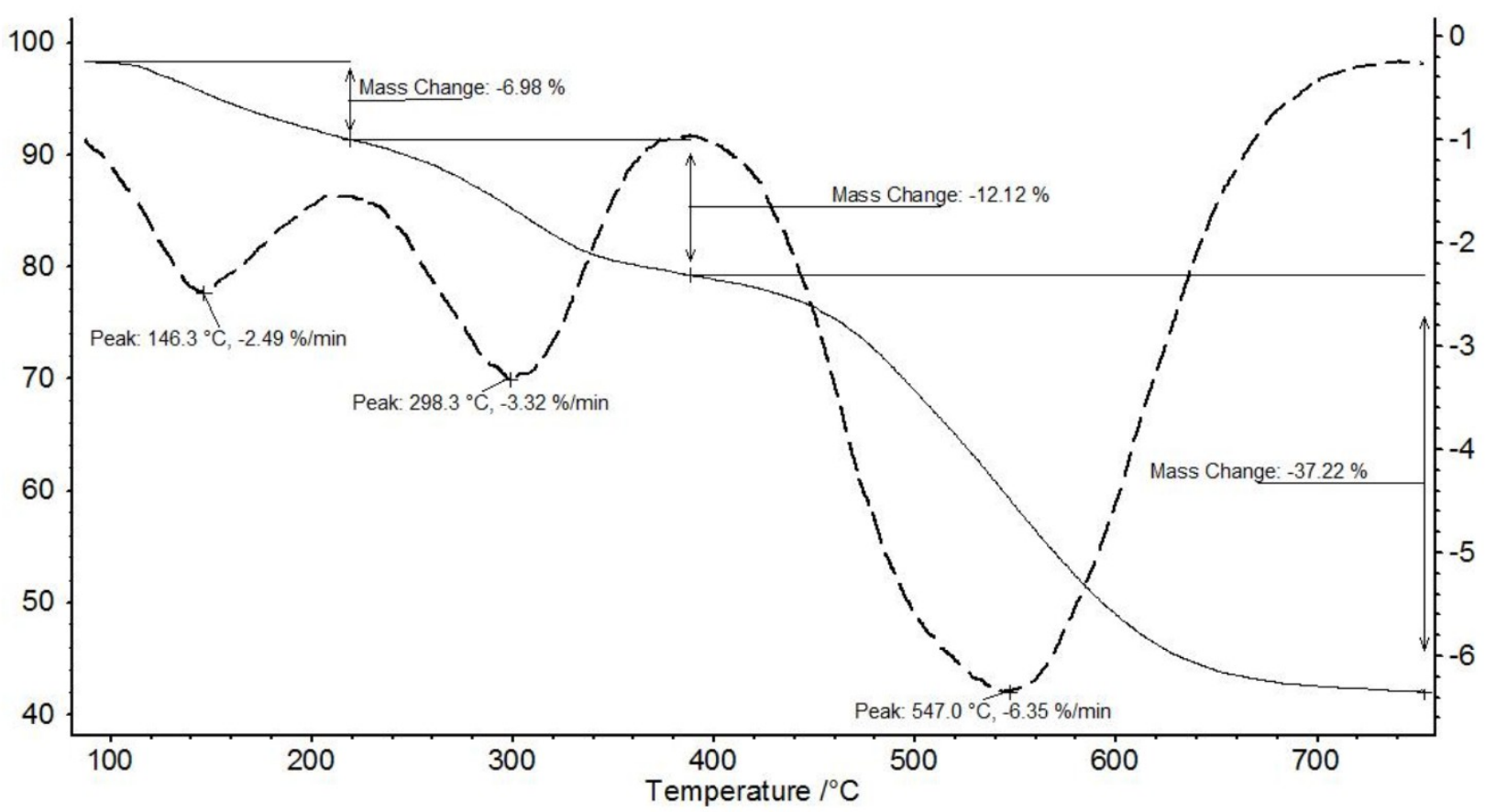

(a)

TG $/ \%$

DTG /(\%/min)

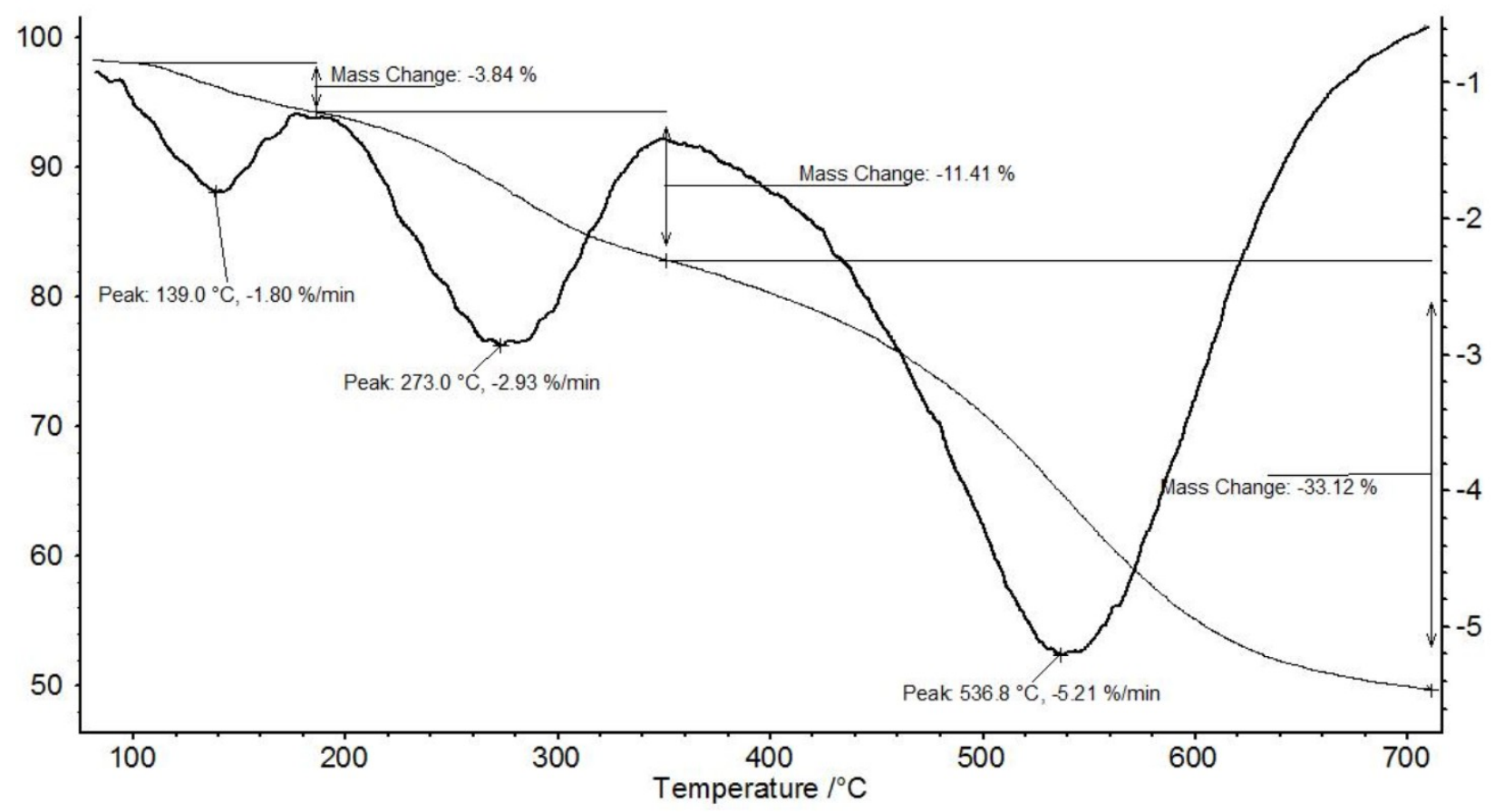

(b)

Figure 2. TGA thermograms of PANI (a), and PANI/BC composite (b).

It has been conducted that PANI is not much thermally stable as an organic polymer. In contrast, the PANI/BC composite showed a lower weight loss at every thermal step that can be related to improved thermal stability. This indicates that biochar particles enhanced the thermal stability of
PANI making it favorable in high temperature applications.

\section{UV/Vis absorbance analysis}

In the literature, it is discovered that the removal percentages of $\mathrm{Cu}(\mathrm{II})$ ions increase with an increase of initial ion concentration between 50-600 ppm 
(57). However, a higher concentration of $\mathrm{Cu}$ (II) has been found to reduce the adsorption capacity due to the saturation of the adsorption sites. Therefore, in this study the initial ion concentration of $\mathrm{Cu}(\mathrm{II})$ ions was determined as $200 \mathrm{ppm}$ as reported from literature $(57,58) .10$ working solutions $(20,40,60$, $80,100,120,140 \ldots 200 \mathrm{mg} / \mathrm{L})$ were prepared by diluting the stock solutions of copper(II) nitrate using distilled water.

The absorbance values were determined by using SHIMADZU, Double Beam UV-Vis Spectrophotometer/UV-2600 device at proper wavelength for $\mathrm{Cu}^{2+}$ ions $(450 \mathrm{~nm})$. These absorbance values were plotted with the concentrations of solutions as shown in Figure 3.

UV/Vis spectroscopy is widely performed available technique for adsorption characterization of prepared adsorbent samples. Adsorption capacities of prepared adsorbents for heavy metal ions can be studied by using UV/Vis spectroscopy. Spectral analysis was applied with a SHIMADZU, Double

Table 1. Removal percentages determined with UV spectrometry.

\begin{tabular}{ccccc}
\hline $\begin{array}{l}\mathbf{p} \\
\mathbf{H}\end{array}$ & $\begin{array}{l}\mathbf{T} \\
\left({ }^{\circ} \mathbf{C}\right)\end{array}$ & $\begin{array}{l}\text { Adsorbent } \\
\text { Dosage (mg) }\end{array}$ & $\begin{array}{l}\text { Contact } \\
\text { Time }(\mathbf{m i n})\end{array}$ & $\begin{array}{l}\text { Removal } \\
(\%)\end{array}$ \\
\hline 2 & 30 & 20 & 60 & 62.76 \\
\hline 3 & 30 & 20 & 60 & 80.31 \\
\hline 4 & 30 & 20 & 60 & 84.66 \\
\hline 5 & 30 & 20 & 60 & 84.57 \\
\hline 6 & 30 & 20 & 60 & 82.40 \\
\hline 7 & 30 & 20 & 60 & 83.12 \\
\hline 8 & 30 & 20 & 60 & 81.70 \\
\hline 4 & 18 & 20 & 60 & 79.85 \\
\hline 4 & 20 & 20 & 60 & 87.72 \\
\hline 4 & 25 & 20 & 60 & 86.66 \\
\hline 4 & 30 & 20 & 60 & 84.69 \\
\hline 4 & 20 & 5 & 60 & 88.17 \\
\hline 4 & 20 & 10 & 60 & 89.23 \\
\hline
\end{tabular}

\section{Batch experiments}

$p H$ effect: The solute $\mathrm{pH}$ is important in adsorption experiments and generally the influence of $\mathrm{pH}$ parameter was examined prior to the other experimental parameters. The higher removal efficiencies of $\mathrm{Cu}(\mathrm{II})$ ions were founded when the $\mathrm{pH}$ of solution is greater than 4 since the decomposition rate occurred more slowly on the adsorbent surface under $\mathrm{pH}$ 4. The decrease in solute $\mathrm{pH}$ showed the lower tendency of removal efficiency for the PANI/BC composite adsorbents that can be associated with
Beam UV-Vis Spectrophotometer/UV-2600 device as collecting spectra from 200-1100 nm. Deuterium and tungsten lamps are preferred to obtain illumination across the ultraviolet, visible, and nearinfrared electromagnetic spectrum.

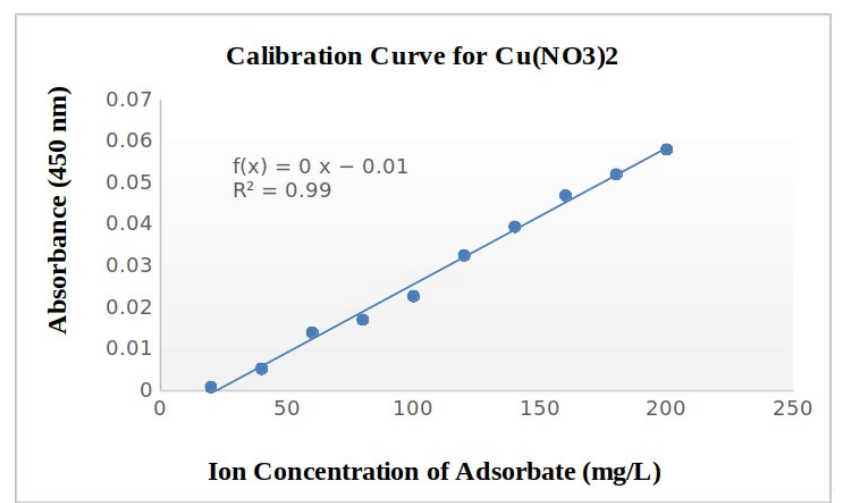

Figure 3. The calibration equation and calibration curve.

\begin{tabular}{ccccc}
4 & 20 & 15 & 60 & 87.72 \\
\hline 4 & 20 & 20 & 60 & 87.72 \\
4 & 20 & 30 & 60 & 86.66 \\
\hline 4 & 20 & 40 & 60 & 86.51 \\
\hline 4 & 20 & 50 & 60 & 86.66 \\
\hline 4 & 20 & 100 & 60 & 86.51 \\
\hline 4 & 20 & 150 & 60 & 85.30 \\
\hline 4 & 20 & 10 & 5 & 85.45 \\
\hline 4 & 20 & 10 & 15 & 86.21 \\
\hline 4 & 20 & 10 & 30 & 83.34 \\
\hline 4 & 20 & 10 & 60 & 88.17 \\
\hline 4 & 20 & 10 & 120 & 87.42 \\
\hline 4 & 20 & 10 & 180 & 88.33 \\
\hline 4 & 20 & 10 & 240 & 88.03 \\
\hline 4 & 20 & 10 & 300 & 88.48 \\
\hline
\end{tabular}

higher acidic conditions due to the protonation of the groups.

In usual, water adsorption can occur easily on the surface of biochar, which is due to the covered eventual adsorbent surface layer with hydroxyl groups. These hydroxyls groups can take and leave protons to the water as making the adsorbent surface positively or negatively charged (59). 


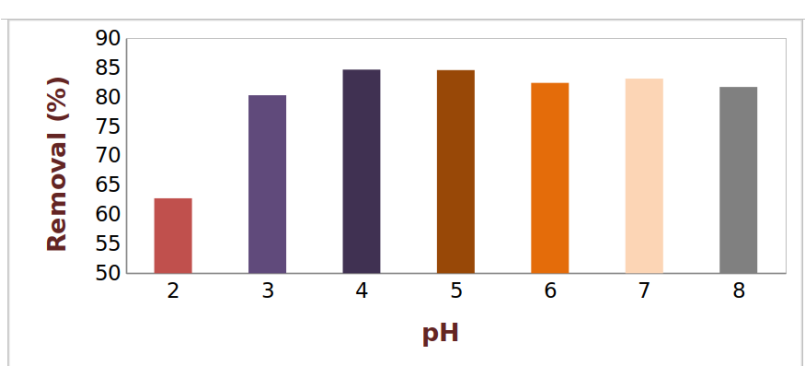

Figure 4. At $30^{\circ} \mathrm{C}$, the $\mathrm{pH}$ effect examination for $20-\mathrm{mg}$ amounts of PANI/BC composite adsorbent for 60 min of contact time.

If the acidic properties of the adsorbent surface are higher than the solute, the surface is charged negatively since the surface release protons to the solvent. In contrast, the surface is charged positively since the particle receives protons from the solvent due to the basic characteristic of the adsorbent surface (59).

As shown in Figure 4, it can be concluded that the $\mathrm{pH}$ values between 3 and 6 promote the adsorption mechanism of $\mathrm{Cu}(\mathrm{II})$ ions due to nitrogen-containing functional groups in the polymeric chain including amine, imine, and protonated imine as responsible sites for adsorption.

Temperature effect: Temperature is a vital parameter for both adsorption rate and equilibrium conditions as it is changing the molecular interactions and solubility (60).

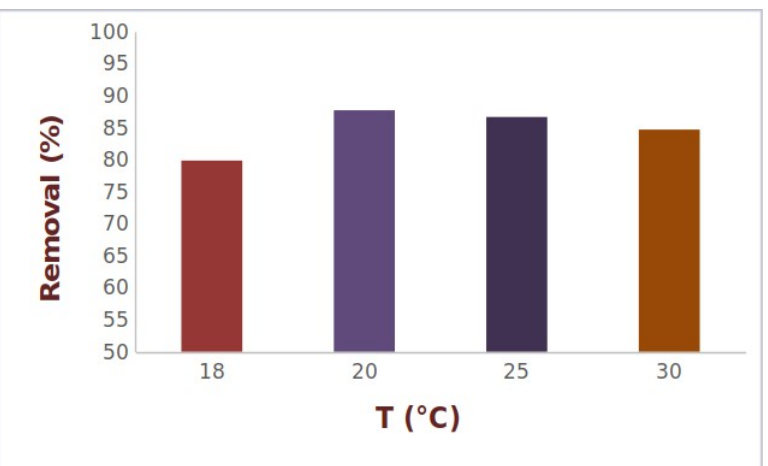

Figure 5. At pH 4 the temperature effect examination for 20-mg amounts of PANI/BC composite adsorbents for 60 min of contact time.

The adsorption of $\mathrm{Cu}(\mathrm{II})$ ions on PANI/BC composite adsorbent was examined at temperatures of 18, 20, 25 , and $30{ }^{\circ} \mathrm{C}$. As shown in Figure 5, the removal efficiency of adsorbent samples at $20^{\circ} \mathrm{C}$ is higher than the removal efficiency at $18{ }^{\circ} \mathrm{C}$, which can be associated with the increment of adsorption rate with temperature effect. The increase of temperature accelerates the mobility of $\mathrm{Cu}$ (II) ions on the adsorbent surface. The increase of removal efficiency of adsorbent from 18 to $20^{\circ} \mathrm{C}$ also shows the spontaneous and feasibility of the adsorption mechanism. Adsorption efficiency can also decrease with the decrease of temperature effect in physical adsorption process due to the endothermic nature of mechanism. However, it was observed that the removal efficiency decreased with the increasing of temperature from 20 to $30^{\circ} \mathrm{C}$ may be due to the physical adsorption behavior. In physical adsorption with increasing temperature, weaker physical attractions occur between the adsorbent surface and aqueous solution(61).

Dosage effect: Experimental studies were repeated with different dosages of PANI/BC to examine the effect of adsorbent dosage on removal efficiency and the results are given in Figure 6 . The adsorbent amount is a very effective parameter as it defines the extent of removal. Increasing the adsorbent amount from 5 to $100 \mathrm{mg}$ resulted in a sharp decrease in the percentage removal for $\mathrm{Cu}(\mathrm{II})$ ions. This behavior can be also observed probably due to overlapping functional sites at higher adsorbent amounts. 


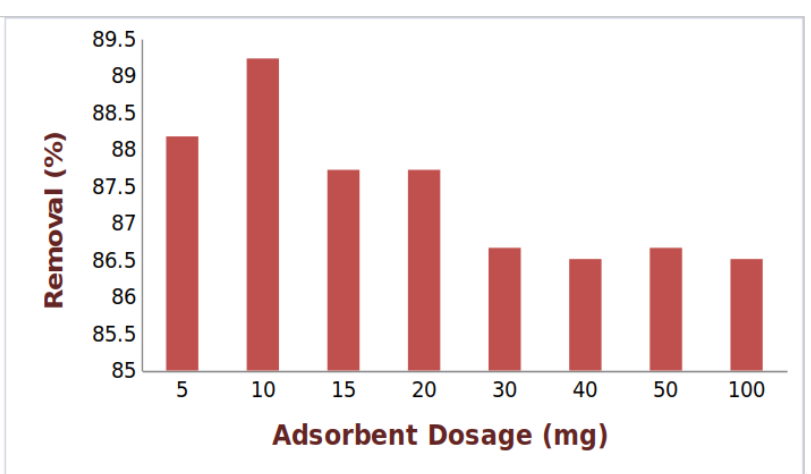

Figure 6. At $\mathrm{pH} 4$, the adsorbent dosage effect examination of PANI/BC composite adsorbents for $20^{\circ} \mathrm{C}$ temperature and 60 min contact time.

Besides, the driven forces between adsorbent surface and solution physically obstruct available adsorption sites as leading to adsorption capacity decrease. In general, decreasing effective binding sites can be associated with the agglomeration of exchange particles (62).

On the other hand, the removal efficiency of $\mathrm{Cu}(\mathrm{II})$ increased from $88.17 \%$ to $89.23 \%$ with an increase of the adsorbent amount from $5 \mathrm{mg}$ to $10 \mathrm{mg}$ for $1 \mathrm{~h}$ of contact time. This increase in the adsorption can be related more availability of binding sites on the adsorbent surface to yield complexes with metal ions. The copper removal almost remains unchanged after $(0.3 \mathrm{~g})$ dosage of adsorbent is added since the adsorption equilibrium is reached. The maximum removal efficiency for PANI/BC composite was found at an adsorbent dosage of 10 $\mathrm{mg}$ of the composite at $20^{\circ} \mathrm{C}$ and for $1 \mathrm{~h}$ of contact time in the adsorption batch experiment as can be seen from Figure 6.

The effect of contact time: The contact time explains the rate of the binding possibility of metal ions on the adsorbent surface and gives the optimum contact time for removal process completion of the metal ions. Figure 7 indicates the contact time effect on the removal efficiency of PANI/BC composite adsorbent. The removal efficiency increases with time and achieves equilibrium within $180 \mathrm{~min}$. The metal ion adsorption changes with time increase thanks to saturation, considering that the possibility of monolayer covering of metal ions on the adsorbent surface.

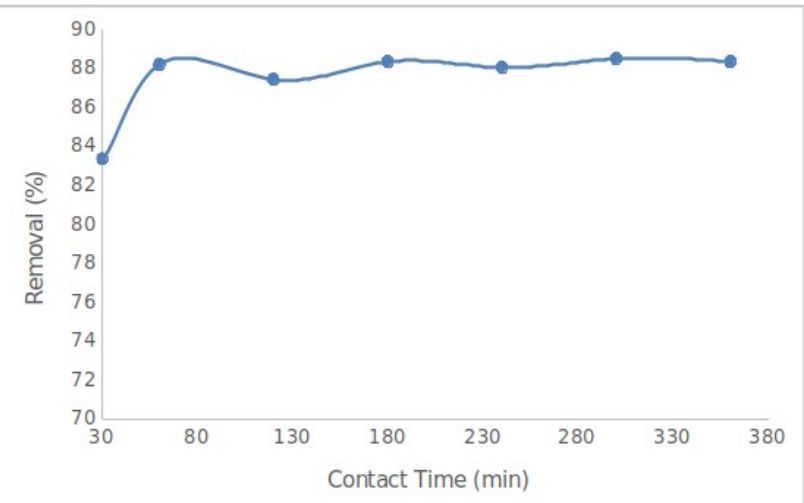

Figure 7. At $\mathrm{pH} 4$, the contact time effect examination for 10-mg amounts of PANI/BC composite adsorbents for $20^{\circ} \mathrm{C}$ temperature.

As shown in figures, the relationship between the effecting experimental variables such as $\mathrm{pH}$, contact time, temperature, and their related removal abilities contains highly non-linear complex behavior for various adsorbent substances. Therefore, it is generally very difficult to estimate the most promising operational conditions of different adsorbent types for improving the adsorption capacity. Besides, the experimental set up of these mechanisms can be time-consuming and highly costly. However, models are one of the best alternatives to avoid these limitations.

\section{Kinetic analysis of PANI/BC composite adsorbent}

The kinetic studies show the rate of the chemical reaction during the adsorption processes and define the effecting parameters of these reactions for the equilibrium access with an acceptable amount of time. The simulations of kinetic models give also hints about for the adsorption mechanisms and adsorption capacities. 
One of the most preferred kinetic models are the Linearized Pseudo First-Order and Pseudo Second Order models. The linearised pseudo-first-order kinetic model formulation can be expressed as the following statement (63):

$$
\ln \left(q_{e}-q_{t}\right)=\ln q_{e}-k_{1} t
$$

Where $k_{1}\left(\mathrm{~min}^{-1}\right)$ denotes the pseudo-first-order adsorption rate constant, whereas the $\mathrm{q}_{\mathrm{e}}$ and $\mathrm{q}_{\mathrm{t}}$ are the expressions of the adsorbed mass amounts of adsorbent $(\mathrm{mg} / \mathrm{g})$ at equilibrium time and $\mathrm{t}(\mathrm{min})$ time, respectively. In general, the pseudo-first-order kinetic models which change significantly according to the adsorption mechanism are appropriate for only the first 20 and 30 contact minutes of adsorbents.

The linearized Pseudo second-order kinetic model can also be formulated as the following statement (64):

$$
\frac{t}{q_{t}}=\frac{1}{k_{2} q_{e}^{2}}+\frac{1}{q_{e}} \times t
$$
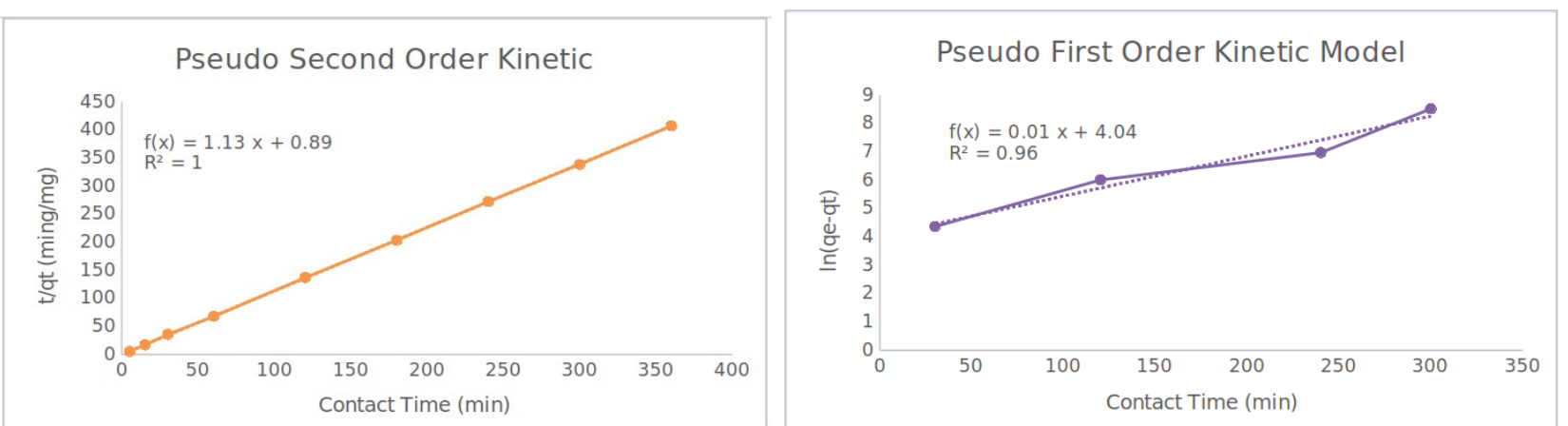

Figure 8. The comparison of PANI/BC composite adsorbent results with Pseudo Second Order Kinetic Model (top) and with Pseudo First Order Kinetic Model (bottom).

As seen in Figure 8, the pseudo-second-order model fits better with the experimental results because it gives a higher determination coefficient factor (1) than the pseudo-first-order model result (0.9612). Pseudo-second-order kinetic model can be considered as the proper model for the adsorption process of $\mathrm{Cu}(\mathrm{II})$ onto the PANI/BC composite adsorbent due to its high determination coefficient value and its validity for almost every contact time variety.
Where $\mathrm{k}_{2}\left(\mathrm{~min}^{-1}\right)$ refers to the pseudo-second-order kinetic model rate constant as can be related to the experimental conditions including the initial solute $\mathrm{pH}$, temperature, etc. When $\mathrm{k}_{2}$ decreases the required time is increased for reaching the equilibrium conditions. The main assumption of the pseudo-second-order kinetics is the adsorption ratelimiting step occurs due to the valency forces of interactions between adsorbent surface and heavy metal ions. $k_{2}\left(\mathrm{~min}^{-1}\right)$ and $q_{e}(\mathrm{mg} / \mathrm{g})$ values can be calculated from the intercept and slope of the plotted curves that were generated by plotting $t / q_{t}$ versus $t(\mathrm{~min})$. If the adsorption process follows these kinetic model results, the plotted curve would be straight line. One of the big advantages of this type of kinetic model is the estimating $q_{e}$ parameters with a relatively small experimental error.

These two different kinetic models were utilized for PANI/BC composite adsorbent material for its predetermined operational conditions such as $\mathrm{pH} 4$ of solute and $20^{\circ} \mathrm{C}$ to investigate the compatibility of the synthesized adsorbent samples with both kinetic models. 


\section{Nonlinear regression model}

Samples: The effect of five variables on the efficiency of $\mathrm{Cu}(\mathrm{II})$ adsorption including; $\mathrm{pH}$, adsorbent dosage, contact time, and temperature were selected as input parameters and utilized to develop the model. All experimental results were divided into training and testing sets. Samples were randomly selected by using the MATLAB software. The training dataset was employed to develop a non-linear regression model and a testing dataset was applied for validation of the proposed model.

Model: Modeling is a proven and accepted engineering approach to design and optimize removal processes by using a nonlinear combination of experimental parameters. This combination is defined as highly complex, which is affected by different operational conditions and adsorption mechanisms. Thus, modeling of removal processes is encouraged by using nonlinear regression. Nonlinear regression technique is a kind of regression analysis in which observational data are modeled by a function that is a nonlinear combination of the model parameters and depends on one or more independent variables.

In this study, an innovative approach is implemented to improve the accuracy of the nonlinear regression and its estimation ability of removal efficiency. The aim is to define optimum operational conditions as input variables associated with removal efficiency and to perform an exponential and logarithmic regression on developed model. The developed model that is used for the estimation of Cu(II) removal, is the following:

Removal Efficiency Prediction for $\mathbf{C u}(\mathrm{II})=(-$ $\left.0.0061916) \times\left(x_{1}\right)\right)+\left((-0.034073) \times\left(x_{2}\right)\right)+(($ $\left.0.30832) \times\left(x_{3}\right)\right)+\left((-13272) \times\left(x_{4}\right)\right)+((-7.8883 \times 10$

$\left.\left.{ }^{10}\right) \times\left(x_{5}\right)\right)+\left(\left(-4.5737 \times 10^{-09}\right) \times\left(x_{6}\right)\right)$

where $x_{1}$ is $\left(\right.$ temp $\left.p^{3} / \mathrm{ph}^{3}\right), x_{2}$ is $(($ time $/ p h) \times \cos (p h)), x_{3}$ is $\left(\cos \left(\operatorname{mass}^{2}\right) \times \cot \left(\right.\right.$ time $\left./ \sin \left(\mathrm{ph}^{0.5}\right)\right), \quad x_{4}$ is $\left(\mathrm{ph}^{3} /\right.$ temp $\left.^{2}\right) /$ temp $^{2}, \quad x_{5}$ is $\left(\right.$ temp $^{7} / \cos \left(\right.$ time $\left.\left.\left.^{2}\right)\right) / \mathrm{ph}\right), x_{6}$ is $\left(\right.$ mass $\left.^{4}\right)$, respectively, and the coefficients from $\gamma_{1}$ to $\gamma_{6}$ denote the regression coefficients.

The comparison between the model results and experimental datasets gave a high correlation coefficient (0.9494) as indicating the $\mathrm{Cu}(\mathrm{II})$ removal estimation ability of the model for PANI/BC composite adsorbent.

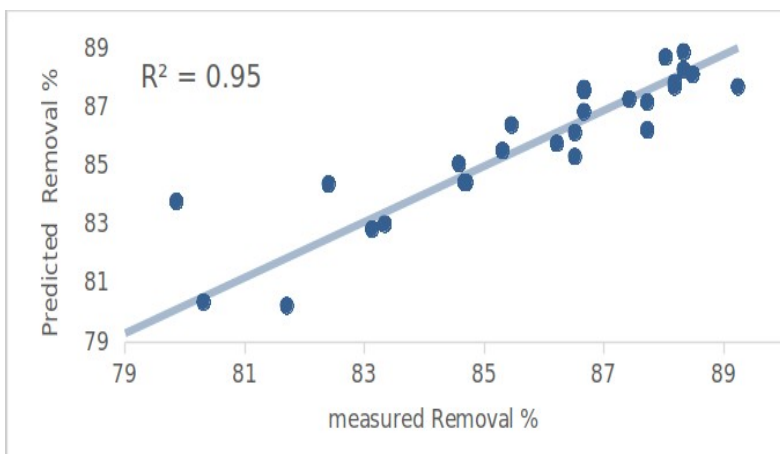

Figure 9. The comparison between the experimental results and the predicted results obtained from the developed non-linear model.

Regression analysis was used to define the consistency of the model output results and the target values showing whether the training network is acceptable or not (Figure 9). In addition, to obtain a better understanding of the model ability, optimal operating parameters obtained from experimental studies were tested with model simulation results. According to experimental results, $\mathrm{pH}$ of the adsorbate solution 4, the adsorbent dosage of 10 $\mathrm{mg}$, and temperature of $20^{\circ} \mathrm{C}$ were determined as the optimum experimental conditions with a removal efficiency of \% 89.23 for PANI/BC composite adsorbent. This value is quite high as considering the many removal percentages obtained from copper removal studies in the literature (65-69). The results demonstrated that the PANI/BC composite was found to be an ideal adsorbent material for the removal of copper metals.

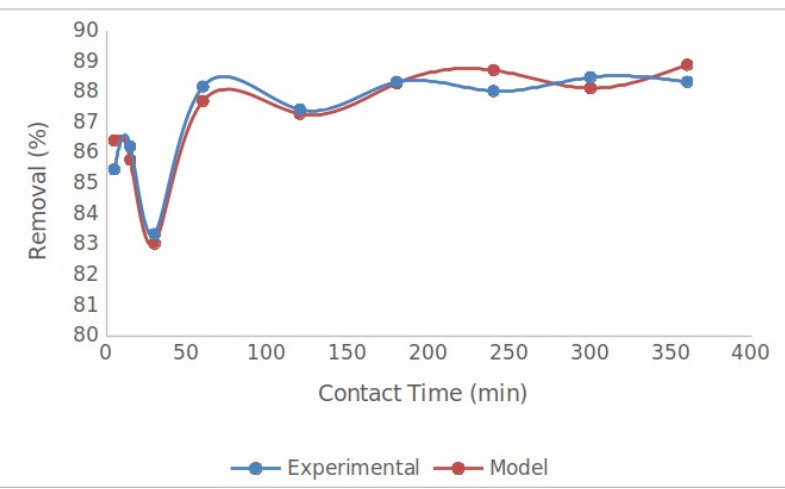

Figure 10. Agreement between the non-linear model and experimental results as a function of contact time.

The impacts of experimental parameters on $\mathrm{Cu}(\mathrm{II})$ ions removal ability were utilized to comprehend the process when the other factors were fixed at the optimum value that conducted in experimental studies. As can be seen in Figure 10, the prediction ability of the proposed model was validated by using the corresponding model simulation results with the experimental outcomes of PANI/BC composite adsorbent. 


\section{CONCLUSION}

In this study, the removal of Cu(II) toxic heavy metal ions from aqueous solution using a novel Polyaniline/Biochar (PANI/BC) composite adsorbents was conducted in batch experiments. The effects of operational parameters such as adsorbent dosage, $\mathrm{pH}$, contact time, and temperature were investigated on the $\mathrm{Cu}(\mathrm{II})$ removal process. The kinetic results showed that the $\mathrm{Cu}(\mathrm{II})$ removal occurs in the 30 min of contact time, which implies a high affinity of adsorbent toward ions, probably due to the functional adsorption sites such as hydroxyl, carboxyl, and amine groups on the adsorbent surface. It was also found that the utilization of a non-linear regression modeling approach is a very effective, economic, and eco-friendly method for comprehending of removal mechanism. Moreover, the optimal conditions of PANI/BC composite for $\mathrm{Cu}(\mathrm{II})$ adsorption experiments showed good agreement with our proposed model. Modeling results were compared with experimental results to verify the predictive accuracy and applicability of the model. According to our expectations, large applicable information about composite materials gained with ease of modeling approach will increase the discovery of advanced materials for future green synthesis components and clean energy systems.

\section{REFERENCES}

1. Rashid N, Rehman MSU, Han J-I. Recycling and reuse of spent microalgal biomass for sustainable biofuels. Biochemical engineering journal. 2013;75:101-7.

2. Patra J, Panda S, Dhal N. Biochar as a low-cost adsorbent for heavy metal removal: A review. Int J Res Biosci. 2017;6:1-7.

3. Sardar K, Ali S, Hameed S, Afzal S, Fatima S, Shakoor MB, et al. Heavy metals contamination and what are the impacts on living organisms. Greener Journal of Environmental Management and Public Safety. 2013;2(4):172-9.

4. Galil N, Rebhun M. Primary chemical treatment minimizing dependence on bioprocess in small treatment plants. Water Sci Technol. 1990;22(3-4):203-10.

5. Kurniawan TA, Chan GY, Lo W-H, Babel S. Physicochemical treatment techniques for wastewater laden with heavy metals. Chem Eng J. 2006;118(1-2):83-98.

6. O'Connell DW, Birkinshaw C, O'Dwyer TF. Heavy metal adsorbents prepared from the modification of cellulose: A review. Bioresource technology. 2008;99(15):6709-24

7. Wang $\mathrm{Y}-\mathrm{H}$, Lin S-H, Juang R-S. Removal of heavy metal ions from aqueous solutions using various low-cost adsorbents. Journal of Hazardous Materials. 2003;102(23):291-302.

8. Fu F, Wang Q. Removal of heavy metal ions from wastewaters: a review. Journal of environmental management. 2011;92(3):407-18.
9. Khezami L, Capart R. Removal of chromium (VI) from aqueous solution by activated carbons: kinetic and equilibrium studies. Journal of hazardous materials. 2005;123(1-3):223-31.

10. Ali I. New generation adsorbents for water treatment. Chemical reviews. 2012;112(10):5073-91.

11. Uzun I, Güzel F. Adsorption of some heavy metal ions from aqueous solution by activated carbon and comparison of percent adsorption results of activated carbon with those of some other adsorbents. Turkish Journal of Chemistry. 2000;24(3):291-8.

12. Biškup B, Subotić B. Kinetic analysis of the exchange processes between sodium ions from zeolite $A$ and cadmium, copper and nickel ions from solutions. Sep Purif Technol. 2004;37(1):17-31.

13. Cincotti A, Mameli A, Locci AM, Orrù R, Cao G. Heavy metals uptake by Sardinian natural zeolites: Experiment and modeling. Ind Eng Chem Res. 2006;45(3):1074-84.

14. Gupta VK, Ali I. Removal of lead and chromium from wastewater using bagasse fly ash - a sugar industry waste. J Colloid Interf Sci. 2004;271(2):321-8.

15. Haroun AA, El-Halawany NR. Preparation and Evaluation of Novel Interpenetrating Polymer NetworkBased on Newspaper Pulp for Removal of Copper Ions. Polym-Plast Technol. 2011;50(3):232-8.

16. Haroun AA, Mashaly HM, El-Sayed NH. Novel nanocomposites based on gelatin/HPET/chitosan with high performance acid red 150 dye adsorption. Clean Technol Envir. 2013;15(2):367-74.

17. Kardam A, Raj KR, Srivastava S, Srivastava MM. Nanocellulose fibers for biosorption of cadmium, nickel, and lead ions from aqueous solution. Clean Technol Envir. 2014;16(2):385-93.

18. Huang Q, Liu MY, Mao LC, Xu DZ, Zeng GJ, Huang $\mathrm{HY}$, et al. Surface functionalized SiO2 nanoparticles with cationic polymers via the combination of mussel inspired chemistry and surface initiated atom transfer radical polymerization: Characterization and enhanced removal of organic dye. J Colloid Interf Sci. 2017;499:170-9.

19. Huang QA, Liu MY, Chen JY, Wan Q, Tian JW, Huang $L$, et al. Facile preparation of MoS2 based polymer composites via mussel inspired chemistry and their high efficiency for removal of organic dyes. Appl Surf Sci. 2017:419:35-44.

20. Zhang XY, Huang Q, Liu MY, Tian JW, Zeng GJ, Li Z, et al. Preparation of amine functionalized carbon nanotubes via a bioinspired strategy and their application in Cu2+ removal. Appl Surf Sci. 2015;343:19-27.

21. Gier S, Johns WD. Heavy metal-adsorption on micas and clay minerals studied by X-ray photoelectron spectroscopy. Applied Clay Science. 2000;16(5-6):289-99.

22. Koppelman M, Dillard J. A study of the adsorption of $\mathrm{Ni}$ (II) and $\mathrm{Cu}$ (II) by clay minerals. Clays and Clay Minerals. 1977;25(6):457-62. 
23. Dang $\mathrm{V}$, Doan $\mathrm{H}$, Dang-Vu $\mathrm{T}$, Lohi A. Equilibrium and kinetics of biosorption of cadmium (II) and copper (II) ions by wheat straw. Bioresource technology. 2009;100(1):211-9.

24. Hadi B, Margaritis A, Berruti F, Bergougnou M Kinetics and equilibrium of cadmium biosorption by yeast cells S. cerevisiae and K. fragilis. Int J Chem React Eng. 2003;1(1).

25. Sharma YC, Uma, Gode F. Engineering Data for Optimization of Preparation of Activated Carbon from an Economically Viable Material. J Chem Eng Data. 2010;55(9):3991-4.

26. Yang T, Lua AC. Textural and chemical properties of zinc chloride activated carbons prepared from pistachionut shells. Mater Chem Phys. 2006;100(2-3):438-44.

27. Foroushani FT, Tavanai $\mathrm{H}$, Hosseini FA. An investigation on the effect of $\mathrm{KMnO} 4$ on the pore characteristics of pistachio nut shell based activated carbon. Microporous and Mesoporous Materials. 2016;230:39-48.

28. Zheng W, Guo MX, Chow T, Bennett DN Rajagopalan N. Sorption properties of greenwaste biochar for two triazine pesticides. Journal of Hazardous Materials. 2010;181(1-3):121-6.

29. Anderson N, Jones J, Page-Dumroese D, McCollum D, Baker S, Loeffler D, et al. A comparison of producer gas, biochar, and activated carbon from two distributed scale thermochemical conversion systems used to process forest biomass. Energies. 2013;6(1):164-83.

30. Liu W-J, Zeng F-X, Jiang H, Zhang X-S. Preparation of high adsorption capacity bio-chars from waste biomass. Bioresource technology. 2011;102(17):8247-52.

31. Nagarale R, Gohil G, Shahi VK. Recent developments on ion-exchange membranes and electromembrane processes. Advances in colloid and interface science. 2006;119(2-3):97-130.

32. Zhou Y, Gao B, Zimmerman AR, Fang J, Sun Y, Cao $X$. Sorption of heavy metals on chitosan-modified biochars and its biological effects. Chemical Engineering Journal. 2013;231:512-8.

33. Wang L-X, Li X-G, Yang Y-L. Preparation, properties and applications of polypyrroles. Reactive and Functional Polymers. 2001;47(2):125-39.

34. Taghizadeh A, Taghizadeh $\mathrm{M}$, Jouyandeh $\mathrm{M}$, Yazdi MK, Zarrintaj P, Saeb MR, et al. Conductive polymers in water treatment: A review. Journal of Molecular Liquids. 2020:113447.

35. Das TK, Prusty S. Review on conducting polymers and their applications. Polymer-plastics technology and engineering. 2012;51(14):1487-500.

36. Laabd M, Hallaoui A, Aarb N, Essekri A, Eljazouli $\mathrm{H}$ Lakhmiri R, et al. Removal of polycarboxylic benzoic acids using polyaniline-polypyrrole copolymer: experimental and DFT studies. Fibers and Polymers. 2019;20(5):896-905.

37. Jiang $Y$, Liu Z, Zeng G, Liu Y, Shao B, Li Z, et al Polyaniline-based adsorbents for removal of hexavalent chromium from aqueous solution: a mini review.
Environmental Science and Pollution Research. 2018;25(7):6158-74.

38. Wang J, Zhu W, Zhang T, Zhang L, Du T, Zhang W, et al. Conductive polyaniline-graphene oxide sorbent for electrochemically assisted solid-phase extraction of lead ions in aqueous food samples. Analytica Chimica Acta. 2020;1100:57-65

39. Yang $\mathrm{Y}$, Wang $\mathrm{W}$, Li $\mathrm{M}$, Wang $\mathrm{H}$, Zhao $\mathrm{M}$, Wang $\mathrm{C}$. Preparation of PANI grafted at the edge of graphene oxide sheets and its adsorption of $\mathrm{Pb}$ (II) and methylene blue. Polymer Composites. 2018;39(5):1663-73.

40. Xia C, Chen W, Wang X, Hedhili MN, Wei N, Alshareef HN. Highly stable supercapacitors with conducting polymer core-shell electrodes for energy storage applications. Advanced Energy Materials. 2015;5(8):1401805.

41. Shao D, Chen C, Wang X. Application of polyaniline and multiwalled carbon nanotube magnetic composites for removal of $\mathrm{Pb}$ (II). Chemical Engineering Journal. 2012;185:144-50.

42. Kim MK, Sundaram KS, Iyengar GA, Lee K-P. A novel chitosan functional gel included with multiwall carbon nanotube and substituted polyaniline as adsorbent for efficient removal of chromium ion. Chemical Engineering Journal. 2015;267:51-64.

43. Ansari MO, Kumar R, Ansari SA, Ansari SP, Barakat $M$, Alshahrie $A$, et al. Anion selective pTSA doped polyaniline@ graphene oxide-multiwalled carbon nanotube composite for $\mathrm{Cr}(\mathrm{VI})$ and Congo red adsorption. Journal of colloid and interface science. 2017;496:407-15.

44. Patel N, Okabe K, Oya A. Designing carbon materials with unique shapes using polymer blending and coating techniques. Carbon. 2002;40(3):315-20.

45. Li X, Cai W, An J, Kim S, Nah J, Yang D, et al. Large-area synthesis of high-quality and uniform graphene films on copper foils. science. 2009;324(5932):1312-4.

46. Liu D, Xia L-J, Qu D, Lei J-H, Li Y, Su B-L. Synthesis of hierarchical fiberlike ordered mesoporous carbons with excellent electrochemical capacitance performance by a strongly acidic aqueous cooperative assembly route. Journal of Materials Chemistry A. 2013;1(48):15447-58.

47. Jin $H$, Wang $X$, Shen $Y$, Gu Z. A high-performance carbon derived from corn stover via microwave and slow pyrolysis for supercapacitors. Journal of Analytical and Applied Pyrolysis. 2014;110:18-23.

48. Qiu B, Xu C, Sun D, Wang Q, Gu H, Zhang X, et al. Polyaniline coating with various substrates for hexavalent chromium removal. Applied Surface Science. 2015;334:714.

49. Mansour M, Ossman M, Farag H. Removal of Cd (II) ion from waste water by adsorption onto polyaniline coated on sawdust. Desalination. 2011;272(1-3):301-5.

50. Laabd M, Chafai H, Essekri A, Elamine M, AlMuhtaseb S, Lakhmiri R, et al. Single and multi-component adsorption of aromatic acids using an eco-friendly polyaniline-based biocomposite. Sustainable materials and technologies. 2017;12:35-43. 
51. Novak JM, Lima I, Xing B, Gaskin JW, Steiner C, Das $\mathrm{K}$, et al. Characterization of designer biochar produced at different temperatures and their effects on a loamy sand. Annals of Environmental Science. 2009.

52. Karri RR, Tanzifi M, Yaraki MT, Sahu J. Optimization and modeling of methyl orange adsorption onto polyaniline nano-adsorbent through response surface methodology and differential evolution embedded neural network Journal of environmental management. 2018;223:517-29.

53. Alonso PEdG. Alternative synthesis methods of electrically conductive bacterial cellulose-polyaniline composites for potential drug delivery application 2017.

54. Mi H, Yang $X$, Li F, Zhuang $X$, Chen $C$, Li $Y$, et al Self-healing silicon-sodium alginate-polyaniline composites originated from the enhancement hydrogen bonding for lithium-ion battery: A combined simulation and experiment study. Journal of Power Sources. 2019;412:749-58.

55. Yakışık H. Polymer nanocomposites: synthesis, characterization and application in heavy-metal removal. 2019.

56. Guo $Y$, Zheng $M$, Chen J. Chemical synthesis, characterization and thermal analysis of polyaniline/copper composite powder. Journal of composite materials. 2008;42(14):1431-8

57. Dandil S, Sahbaz DA, Acikgoz C. Adsorption of Cu (II) ions onto crosslinked Chitosan/Waste Active Sludge Char (WASC) beads: Kinetic, equilibrium, and thermodynamic study. International journal of biological macromolecules. 2019;136:668-75.

58. Ma J, Li T, Liu Y, Cai T, Wei Y, Dong W, et al. Rice husk derived double network hydrogel as efficient adsorbent for $\mathrm{Pb}$ (II), $\mathrm{Cu}$ (II) and $\mathrm{Cd}$ (II) removal in individual and multicomponent systems. Bioresource technology. 2019;290:121793.

59. Hosokawa $M$, Nogi $K$, Naito M, Yokoyama $T$. Nanoparticle technology handbook: Elsevier; 2012.

60. Ahmaruzzaman M, Sharma D. Adsorption of phenols from wastewater. Journal of Colloid and Interface
Science. 2005;287(1):14-24.

61. Aksu Z, Tatlı Ai,, Tunç Ö. A comparative adsorption/biosorption study of Acid Blue 161: Effect of temperature on equilibrium and kinetic parameters. Chemical Engineering Journal. 2008;142(1):23-39.

62. Rahmani A, Mousavi HZ, Fazli M. Effect of nanostructure alumina on adsorption of heavy metals. Desalination. 2010;253(1-3):94-100.

63. Ho YS, Wase DJ, Forster C. Kinetic studies of competitive heavy metal adsorption by sphagnum moss peat. Environmental Technology. 1996;17(1):71-7.

64. Ho Y-S, McKay G. Pseudo-second order model for sorption processes. Process biochemistry. 1999;34(5):45165

65. Ali MB, Wang F, Boukherroub R, Lei W, Xia M. Phytic acid-doped polyaniline nanofibers-clay mineral for efficient adsorption of copper (II) ions. Journal of colloid and interface science. 2019;553:688-98.

66. Kubilay Ş, Gürkan R, Savran A, Şahan T. Removal of Cu (II), Zn (II) and Co (II) ions from aqueous solutions by adsorption onto natural bentonite. Adsorption. 2007;13(1):41-51.

67. Wu S, Li F, Xu R, Wei S, Li G. Synthesis of thiolfunctionalized MCM-41 mesoporous silicas and its application in $\mathrm{Cu}$ (II), $\mathrm{Pb}$ (II), $\mathrm{Ag}$ (I), and $\mathrm{Cr}$ (III) removal. Journal of Nanoparticle Research. 2010;12(6):2111-24.

68. Ghaemi N. A new approach to copper ion removal from water by polymeric nanocomposite membrane embedded with $\gamma$-alumina nanoparticles. Applied Surface Science. 2016;364:221-8

69. Betiha $M$, Moustafa $Y$, Mansour A, Rafik E, Elshahat M. Nontoxic polyvinylpyrrolidonepropylmethacrylate-silica nanocomposite for efficient adsorption of lead, copper, and nickel cations from contaminated wastewater. Journal of Molecular Liquids. 2020:113656. 
